\title{
MANAJEMEN RISIKO KONTRAK UNTUK PROYEK KONSTRUKSI
}

\author{
Candra Yuliana ${ }^{1}$ \\ ${ }^{1}$ Dosen / Program Studi Teknik Sipil / Fakultas Teknik, Universitas Lambung Mangkurat \\ Korespondensi: candrayuliana@unlam.ac.id
}

\begin{abstract}
Construction projects often pose a risk of adverse impact on the cost, time and quality of the project during implementation. The risks are included in the category of dominant risk can be avoided and eliminated. The study was conducted by distributing questionnaires to the expert who competence in the implementation of the project at the Department of Public Works, to determine the risks of any risk identified and the dominant influence of the project. The dominant risk has a risk value between 5 and 25. There are 34 major risks, consisting of 5 unacceptable risk and 29 unacceptable risks. There are 44 action for risk mitigation unacceptable and undesirable.
\end{abstract}

Keywords : contract, risk, risk management, major risk

\section{PENDAHULUAN}

\subsection{Latar belakang}

Permasalahan yang terjadi dalam proyek dengan kontrak lump sum adalah penghitungan volume yang tidak akurat akibat kekurang telitian dalam membaca gambar. Hal ini dapat disebabkan karena waktu penawaran yang relatif singkat antara pengambilan dokumen lelang dengan waktu pemasukan penawaran sehingga perhitungan BOQ dan RAB yang kurang teliti.Resiko lain yang dihadapi dalam proyek dengan sistem kontrak lumpsum adalah kesalahan dalam memprediksi harga material.

Menurut Soeharto I (1996), untuk proyek dengan sistem kontrak lump sum, harga yang telah disepakati merupakan harga yang mengikat [1]. Jika ada perubahan volume maupun perubahan harga material, pihak owner tidak mau tahu dan semua itu menjadi resiko kontraktor. Sedangkan proyek yang menggunakan kontrak unit price dimana yang menjadi acuan adalah Bill of Quantity (BQ) yang dikeluarkan oleh owner. Risiko yang ditanggung oleh kontraktor relatif lebih kecil karena yang dibayarkan adalah jumlah volume pekerjaan riil yang dilakukan.

\subsection{Tujuan penelitian}

Tujuan penelitian ini adalah membuat sistem pengelolaan risiko pada proyek yang menggunakan tipe kontrak lump sum dan unit price dalam tiap tahapan konstruksi mulai dari tahapan lelang, sampai pasca konstruksi dengan cara identifikasi resiko pada proyek dengan kontrak lumpsum dan unit price, menganalisis tingkat resiko serta menentukan cara penanganan resiko untuk proyek dengan type lump sum dan unit price.

\section{KAJIAN PUSTAKA}

\subsection{Manajemen risiko}

Vaughan (1978) mengemukakan beberapa definisi risiko, yaitu, risk is the chance of loss, risk is the possibility of loss, dan risk is uncertainty [2].

Dalam setiap tindakan yang dilakukan pasti memiliki tujuan, demikian pula dengan manajemen resiko. Menurut Darmawi [3], manajemen resiko dilaksanakan untuk mengurangi, menghindari, mengakomodasi suatu resiko melalui sejumlah kegiatan yang berurutan yaitu identifikasi resiko, analisa resiko, pengendalian resiko.

\subsection{Analisis risiko}

Analisis risiko merupakan suatu proses dari identifikasi dan penilaian (assessment). Menurut Godfrey, analisis risiko yang dilakukan secara sistematik dapat membantu untuk mengidentifikasi, menilai dan meranking risiko secara jelas, memusatkan perhatian pada risiko utama, memperjelas batasan tentang batasan 
kerugian, meminimalkan potensi kerusakan apabila timbul keadaan yang paling jelek, mengontrol ketidakpastian dalam proyek, memperjelas dan menegaskan peran setiap orang/badan yang terlibat dalam manajemen risiko [4].

Menurut Thompson dan Perry [5], analisis dan manajemen risiko kualitatif mempunyai dua tujuan yaitu identifikasi risiko dan penilaian awal risiko. Analisis kualitatif akan dapat menentukan yang mana merupakan risiko dominan (major/main risk) dengan mengalikan frekuensi/likelihood dengan konsekuensi dari risiko yang telah teridentifikasi, apabila frekuensi tinggi dan konsentrasi tinggi akan menghasilkan tingkat/derajat risiko tinggi (major risk) dan sebaliknya frekuensi rendah dan konsekuensi rendah akan menghasilkan derajat risiko rendah (minor risk), selanjutnya dilakukan respon/penanganan yang diberikan terhadap risiko-risiko utama, yang disebut mitigasi risiko [4].

Menurut Godfrey [4], menguraikan sumber-sumber risiko termasuk potensi penyebab perubahan dan ketidakpastian dari masing-masing sumber risiko seperti Tabel 1 . Frekuensi (likelihood) adalah peluang terjadinya kerugian yang merugikan, yang dinyatakan dalam jumlah kejadian pertahun [4]. Sedangkan konsekuensi (consequences) merupakan besaran kerugian yang diakibatkan oleh terjadinya suatu kejadian yang merugikan yang dinyatakan dalam nilai uang [4]. Secara umum berdasarkan kecenderungan peluang terjadinya risiko (likehood) dan kosekuensi yang diakibatkan (consequences), risiko dapat diklasifikasikan sebagai (1) Unacceptable, adalah risiko yang tidak dapat diterima dan harus dihilangkan, (2) Undesirable, adalah risiko yang tidak diharapkan dan harus dihindari, (3) Acceptable, adalah risiko yang dapat diterima, dan (4) Negligible, adalah risiko yang sepenuhnya dapat diterima.
Tabel 1. Sumber risiko dan penyebabnya

\begin{tabular}{|c|c|c|}
\hline No. & $\begin{array}{l}\text { Sumber } \\
\text { Risiko }\end{array}$ & $\begin{array}{l}\text { Perubahan ketidakpastian } \\
\text { karena: }\end{array}$ \\
\hline 1. & $\begin{array}{l}\text { Politis } \\
\text { (political) }\end{array}$ & $\begin{array}{l}\text { Kebijakan pemerintah, } \\
\text { opini publik, perubahan } \\
\text { ideologi, kekacauan } \\
\text { (perang, terorisme, } \\
\text { kerusuhan) }\end{array}$ \\
\hline 2. & $\begin{array}{l}\text { Lingkungan } \\
\text { (environment) }\end{array}$ & $\begin{array}{l}\text { Pencemaran/polusi, } \\
\text { kebisingan, opini publik, } \\
\text { dampak lingkungan, } \\
\text { perijinan, kebijakan } \\
\text { internal, peraturan } \\
\text { lingkungan/persyaratan } \\
\text { dampak lingkungan }\end{array}$ \\
\hline 3. & $\begin{array}{l}\text { Perencanaan } \\
\text { (planning) }\end{array}$ & $\begin{array}{l}\text { Persyaratan perijinan, tata } \\
\text { guna lahan, dampak sosial } \\
\text { dan ekonomi }\end{array}$ \\
\hline 4. & $\begin{array}{l}\text { Pemasaran } \\
\text { (market) }\end{array}$ & $\begin{array}{l}\text { Permintaan, persaingan, } \\
\text { kepuasan pelanggan }\end{array}$ \\
\hline 5. & $\begin{array}{l}\text { Ekonomi } \\
\text { (economic) }\end{array}$ & $\begin{array}{l}\text { Inflasi, suku bunga, nilai } \\
\text { tukar, kebijakan keuangan, } \\
\text { pajak }\end{array}$ \\
\hline 6. & $\begin{array}{l}\text { Keuangan } \\
\text { (financial) }\end{array}$ & $\begin{array}{l}\text { Kebangkrutan, } \\
\text { keuntungan, asuransi, } \\
\text { pembagian risiko }\end{array}$ \\
\hline 7. & $\begin{array}{l}\text { Alami } \\
\text { (natural) }\end{array}$ & $\begin{array}{l}\text { Kondisi tak terduga, } \\
\text { cuaca, gempa, kebakaran, } \\
\text { penemuan purbakala }\end{array}$ \\
\hline 8. & $\begin{array}{l}\text { Proyek } \\
(\text { project })\end{array}$ & $\begin{array}{l}\text { Perencanaan dan } \\
\text { pengendalian kualitas, } \\
\text { tenaga kerja }\end{array}$ \\
\hline 9. & $\begin{array}{l}\text { Teknis } \\
\text { (technical) }\end{array}$ & $\begin{array}{l}\text { Kelengkapan desain, } \\
\text { keandalan, efisiensi } \\
\text { operasional, ketahanan uji. }\end{array}$ \\
\hline 10. & $\begin{array}{l}\text { Manusia } \\
\text { (human) }\end{array}$ & $\begin{array}{l}\text { Kesalahan, tidak kompeten, } \\
\text { kelalaian, budaya, } \\
\text { kemampuan komunikasi, } \\
\text { ketidaktahuan, bekerja } \\
\text { dalam gelap/malam hari }\end{array}$ \\
\hline 11. & $\begin{array}{l}\text { Criminal } \\
\text { (criminal) }\end{array}$ & $\begin{array}{l}\text { Perusakan, pencurian, } \\
\text { penipuan, korupsi, } \\
\text { kurangnya keamanan }\end{array}$ \\
\hline 12. & $\begin{array}{l}\text { Keselamatan } \\
\text { (safety) }\end{array}$ & $\begin{array}{l}\text { K3, zat berbahaya, ledakan, } \\
\text { kebakaran, } \\
\text { tabrakan/benturan, } \\
\text { keruntuhan }\end{array}$ \\
\hline
\end{tabular}




\subsection{Penilaian risiko (Assessment risk)}

Risiko dapat dikategorikan berdasarkan tingkat dampak risiko yang terjadi. Kategori risiko utama (major risks), mempunyai dampak besar dan luas, yang membutuhkan pengelolaan, sedangkan kategori risiko minor (minor risks), tidak memerlukan penanganan khusus karena tingkat risiko ada dalam batas-batas yang dapat diterima. Skala frekuensi yaitu sangat sering (skala 5), sering (skala 4), kadang-kadang (skala 3), jarang (skala 2) dan sangat jarang (skala 1). Ketentuan besarnya skala konsekuensi yaitu sangat besar (skala 5), besar (skala 4), sedang (skala 3), kecil (skala 2) dan sangat kecil (skala 1).

\subsection{Penerimaan risiko (Risk acceptability)}

Analisis penerimaan risiko (risk acceptability) ditentukan berdasarkan nilai risiko yang diperoleh dari hasil perkalian antara kemungkinan (likelihood) dengan konsekuensi (concequense). Skala penerimaan risiko tersebut adalah skala $\geq 15$ merupakan risiko unacceptable, skala $5 \leq x<15$ merupakan risiko underesirable, skala $3 \leq x<5$ merupakan risiko acceptable, dan skala $x<3$ merupakan risiko negligible [2].

\subsection{Penanganan / Mitigasi risiko (Risk mitigation)}

Mitigasi/penanganan adalah tindakan yang dilakukan untuk menghilangkan atau mengurangi risiko yang telah teridentifikasi. Flanagan dan Norman [6] menguraikan ada 4 cara untuk melakukan mitigasi risiko antara lain menahan risiko (Risk Retention), mengurangi risiko (Risk Reduction), memindahkan risiko (Risk Transfer), dan menghindari risiko (Risk Avoidance).

\section{METODE PENELITIAN}

Responden yang dipilih berdasarkan metode purposif sampling, yaitu para pihak yang terlibat dalam pelaksanaan proyek konstruksi pada bidang Bina Marga Dinas Pekerjaan Umum Kabupaten Gunung Mas. Responden dapat memberikan opini secara terbuka mengenai tindakan mitigasi yang perlu dilakukan untuk menghadapi dan mengurangi risiko yang terjadi. Sumber data atau respondennya yaitu Project Manager dan Site Manager dari pembangunan Christian Center, PP2IB, Sport Center, dan Pasar Kahayan Modern.
Skala penilaian dalam kuesioner menggunakan skala likert. Menurut Ruslan (2003) skala likert disebut juga sebagai method of sumated ratings, yang berarti nilai peringkat setiap jawaban atau tanggapan [7]. Skala likert secara umum menggunakan peringkat lima angka penilaian yaitu, sangat setuju nilai 5, setuju nilai 4 , tidak pasti nilai 3 , tidak setuju nilai 2 , dan sangat tidak setuju nilai 1 .

Data dianalisis berdasarkan penerimaan risiko (risk acceptability) dan menentukan risiko-risiko yang memerlukan tindakan mitigasi. Adapun kriteria risiko yang memerlukan tindakan mitigasi adalah semua risiko yang unacceptable dan undesirable.

\section{ANALISIS DATA DAN HASIL}

Risiko yang teridentifikasi pada proyek konstruksi pada Bidang Bina Marga Dinas Pekerjaan Umum Kabupaten Gunung Mas sebanyak 48 risiko dan 9 kategori sumber risiko yaitu: proyek, teknis, lingkungan, keselamatan, ekonomi, criminal, alami, manusiawi dan keuangan. Jumlah risiko terbanyak bersumber dari aktivitas proyek yang menunjukkan bahwa risiko-risiko khususnya pada tahap pelaksanaan lebih banyak muncul karena teknis pekerjaan di lapangan sangat dekat bersinggungan dengan lingkungan sekitar proyek beserta segala aktivitasnya.

Penilaian risiko untuk setiap variabel dilakukan dengan mengalikan kemungkinan (likelihood) dan pengaruh (consequences), dimana nilai likelihood dan consequences didapat dari hasil kuesioner. Berdasarkan hasil perkalian tersebut diperoleh nilai risiko untuk dapat menentukan tingkat penerimaan risiko (acceptability of risk). Misalnya untuk variabel keterlambatan penandatanganan kontrak mempunyai nilai modus untuk likelihood pada skala 4 dan untuk consequences pada skala 3, maka nilai risikonya adalah 12 . Kemudian nilai risiko tersebut dikategorikan berdasarkan skala penerimaan risiko.

Dari 48 risiko tersebut, ada 34 risiko $(70,84 \%)$ yang merupakan risiko dominan (major risk) yang memerlukan tindakan mitigsi risiko, dengan kategori unacceptable (skala $x \geq$ 15) dan kategori undesirable (skala $5 \leq x<15$ ). Untuk risiko yang lainnya yaitu sebanyak 14 risiko termasuk risiko yang bukan dominan (skala $x<3$ ) sehingga risiko tersebut dapat diterima dan diabaikan. Hasil dari mitigasi 
risiko dapat dilihat pada Tabel 2 dan 3 (pada apendik).

\section{KESIMPULAN}

(a) Risiko pada pelaksanaan proyek konstruksi pada Bidang Bina Marga Dinas Pekerjaan Umum Kabupaten Gunung Mas teridentifikasi 48 risiko.

(b) Ada 34 risiko dominan, terdiri dari 5 risiko unacceptable dan 29 risiko, undesirable berasal dari risiko proyek.

(c) Pada risiko unacceptable ada 8 tindakan mitigasi, dan pada risiko undesirable ada 36 tindakan mitigasi. Mitigasi risiko dilakukan agar dapat mengurangi risiko yang mempengaruhi terjadinya addendum kontrak akibat ketidak sesuaiaan biaya, mutu dan waktu, serta menghindari dari sanksi-sanksi denda keterlambatan dan pemutusan kontrak oleh pihak pemilik proyek kepada kontraktor pelaksana.

\section{DAFTAR PUSTAKA}

[1] Soeharto I, Manajemen Proyek: dari Konseptual Sampai Operasional. Jakarta: Erlangga. 1999

[2] Vaughan, E. J, Fundamental of Risk and Insurance. Second Edition. New York. John Willey \& sons, Inc, 1978

[3] Darmawi, H, Manajemen Risiko. Cetakan Kesepuluh. Jakarta: Bumi Aksara, 2006

[4] Godfrey, P.S., Sir William Halcrow and Partners Ltd., Control of Risk A Guide to Systematic Management of Risk from Construction. Wesminster London: Construction Industry Research and Information Association (CIRIA), 1996

[5] Thompson, P.A. dan Perry, J.G., Engineering Construction Risk. London : Thomas Telford Ltd., 1991

[6] Flanagan, R. dan Norman, G., Risk Management and Construction. Cambridge : University Press, 1993.

[7] Ruslan, Rosady, Metode Penelitian Public Relation dan Komunikasi. Jakarta; PT. Raja Grafindo Persada, 2003.

\section{APENDIK}

Tabel 2. Mitigasi risiko unacceptable

\begin{tabular}{|c|c|c|c|c|}
\hline No & Faktor Risiko & $\begin{array}{c}\text { Nilai } \\
\text { Risiko }\end{array}$ & Tindakan Mitigasi & Keterangan \\
\hline \multicolumn{5}{|c|}{ A. Risiko Manusiawi } \\
\hline 1 & $\begin{array}{l}\text { Kelelahan akibat banyaknya } \\
\text { pekerjaan yang dilakukan } \\
\text { secara lembur }\end{array}$ & 15 & $\begin{array}{l}\text { Menerapkan sistem kerja bergilir } \\
\text { sehingga para pekerja dapat } \\
\text { memulihkan kondisinya }\end{array}$ & $\begin{array}{l}\text { Untuk } \\
\text { menghindari } \\
\text { addendum }\end{array}$ \\
\hline 2 & $\begin{array}{l}\text { Ketidak sesuaian antara } \\
\text { volume } \\
\text { pekerjaan di dalam BQ dan } \\
\text { kondisi di lapangan }\end{array}$ & 16 & $\begin{array}{l}\text { a. mengadakan perhitungan } \\
\text { ulang terhadap volume } \\
\text { pekerjaan dan mengusulkan } \\
\text { pekerjaan tambah kurang } \\
\text { b.membahas perubahan volume } \\
\text { pekerjaan dengan pekerjaan } \\
\text { tambah kurang melalui } \\
\text { amandemen kontrak } \\
\end{array}$ & $\begin{array}{l}\text { Untuk mengindari } \\
\text { tidak sesuainya } \\
\text { volume }\end{array}$ \\
\hline 3 & $\begin{array}{l}\text { Terlambatnya pasokan } \\
\text { material } \\
\text { yang mengurangi kinerja } \\
\text { Pekerjaan }\end{array}$ & 20 & $\begin{array}{l}\text { a. membuat schedule dan } \\
\text { mengevaluasi kedatangan dan } \\
\text { jumlah material yang } \\
\text { disesuaikan dengan kebutuhan } \\
\text { di lapangan } \\
\text { b. melakukan perhitungan jumlah } \\
\text { material yang dibutuhkan } \\
\text { dilapangan memastikan agar } \\
\text { barang siap untuk dikirim } \\
\text { langsung }\end{array}$ & $\begin{array}{l}\text { Untuk } \\
\text { menghindari } \\
\text { addendum }\end{array}$ \\
\hline 4 & $\begin{array}{l}\text { Penggunaan alat berat yang } \\
\text { sudah tua, sehingga } \\
\text { sering mengalami kerusakan } \\
\text { dan memperlambat kinerja }\end{array}$ & 16 & $\begin{array}{l}\text { a. mengevaluasi penggunaan alat } \\
\text { berat yang sudah tua } \\
\text { b. Mencari alat alternatif }\end{array}$ & $\begin{array}{l}\text { Untuk } \\
\text { menghindari } \\
\text { addendum }\end{array}$ \\
\hline
\end{tabular}




\begin{tabular}{c|l|c|l|l}
\hline No & \multicolumn{1}{|c|}{ Faktor Risiko } & $\begin{array}{c}\text { Nilai } \\
\text { Risiko }\end{array}$ & Tindakan Mitigasi & Keterangan \\
\hline B & Risiko Alami & & & \\
\hline 5 & $\begin{array}{l}\text { Terhambatnya pekerjaan } \\
\text { akibat } \\
\text { cuaca (hujan dan banjir). }\end{array}$ & 16 & $\begin{array}{l}\text { melakukan penjadwalan pekerjaan } \\
\text { yang besar seperti pengecoran dan } \\
\text { pengaspalan agar tidak sampai } \\
\text { memasuki musim hujan }\end{array}$ & $\begin{array}{l}\text { Untuk } \\
\text { menghindari } \\
\text { addendum }\end{array}$ \\
\hline
\end{tabular}

Tabel 3. Mitigasi risiko undesirable

\begin{tabular}{|c|c|c|c|c|}
\hline No & Faktor Risiko & $\begin{array}{l}\text { Nilai } \\
\text { Risiko }\end{array}$ & Tindakan Mitigasi & Keterangan \\
\hline \multicolumn{5}{|c|}{ A. Risiko Manusiawi } \\
\hline 1 & $\begin{array}{l}\text { Terjadi keterlambatan } \\
\text { penandatanganan kontrak }\end{array}$ & 12 & $\begin{array}{l}\text { Menyesuaikan jadwal yang sudah } \\
\text { ditetapkan dalam pengurusan } \\
\text { penanda tangan kotrak }\end{array}$ & $\begin{array}{l}\text { Untuk } \\
\text { menghindari } \\
\text { addendum }\end{array}$ \\
\hline 2 & $\begin{array}{l}\text { Keterlambatan penyerahan } \\
\text { kontrak }\end{array}$ & 8 & $\begin{array}{l}\text { Kontraktor harus proaktif dan } \\
\text { selalu memantau serta koordinasi } \\
\text { tentang kendala apa saja yang } \\
\text { menyebabkan keterlambatan } \\
\text { penyerahan kontrak }\end{array}$ & $\begin{array}{l}\text { Menhindari sanksi } \\
\text { keterlambatan }\end{array}$ \\
\hline 3 & $\begin{array}{l}\text { Proses adminstrasi addendum } \\
\text { kontrak }\end{array}$ & 12 & $\begin{array}{l}\text { a. Secepatnya mengajukan surat } \\
\text { permohonan untuk owner agar } \\
\text { memproses permintaan } \\
\text { addendum } \\
\text { b. melengkapi syarat-syarat } \\
\text { administrasi dan teknis untuk } \\
\text { proses addendum }\end{array}$ & $\begin{array}{l}\text { Menhindari sanksi } \\
\text { keterlambatan }\end{array}$ \\
\hline 4 & $\begin{array}{l}\text { Produktivitas pekerja yang } \\
\text { rendah }\end{array}$ & 8 & $\begin{array}{l}\text { membuat schedule kerja yang } \\
\text { lebih ketat serta merencanakan } \\
\text { kerja lembur }\end{array}$ & $\begin{array}{l}\text { Menhindari sanksi } \\
\text { keterlambatan }\end{array}$ \\
\hline 5 & $\begin{array}{l}\text { Keterlambatan kedatangan } \\
\text { tenaga kerja akibat libur } \\
\text { hari raya }\end{array}$ & 8 & $\begin{array}{l}\text { a. Membatasi libur tenaga kerja } \\
\text { b. Mangadakan kesepakatan } \\
\text { dengan penyedia tenaga } \\
\text { kerjaentang waktu libur tenaga } \\
\text { kerja dan kapan tenaga kerja } \\
\text { kembali ke proyek } \\
\text { c. Mencari alternatif tenaga kerja } \\
\text { lain sebagai cadangan }\end{array}$ & $\begin{array}{l}\text { Untuk } \\
\text { menghindari } \\
\text { addendum }\end{array}$ \\
\hline 6 & Pemogokan oleh tenaga kerja & 8 & $\begin{array}{l}\text { memberikan honor tenaga kerja } \\
\text { tepat waktu untuk mencegah } \\
\text { terjadinya pemogokan dan } \\
\text { menyiapkan tenaga } \\
\text { kerja cadangan sebagai antisipasi } \\
\text { jika terjadi pemogokan }\end{array}$ & $\begin{array}{l}\text { Untuk } \\
\text { menghindari } \\
\text { addendum }\end{array}$ \\
\hline \multicolumn{5}{|c|}{ B. Risiko Proyek } \\
\hline 7 & $\begin{array}{l}\text { Pengukuran lapangan untuk } \\
\text { menetukan posisi, titik, garis } \\
\text { dan ketinggian tidak sesuai } \\
\text { Gambar }\end{array}$ & 8 & $\begin{array}{l}\text { mengadakan koordinasi antara } \\
\text { pihak kontraktor, konsultan dan } \\
\text { owner untuk menyesuaikan } \\
\text { pengukuran dengan gambar } \\
\text { rencana }\end{array}$ & $\begin{array}{l}\text { Untuk } \\
\text { menghindari } \\
\text { kesalahan } \\
\text { pekerjaan }\end{array}$ \\
\hline 8 & $\begin{array}{l}\text { Pengukuran dilakukan secara } \\
\text { manual tanpa pesawat ukur } \\
\text { (teodolit) }\end{array}$ & 6 & $\begin{array}{l}\text { melakukan pengukuran ulang yang } \\
\text { lebih akurat agar ukuran di } \\
\text { lapangan lebih presisi }\end{array}$ & $\begin{array}{l}\text { Untuk } \\
\text { menghindari } \\
\text { addendum }\end{array}$ \\
\hline
\end{tabular}




\begin{tabular}{|c|c|c|c|c|}
\hline No & Faktor Risiko & \begin{tabular}{|c|} 
Nilai \\
Risiko
\end{tabular} & Tindakan Mitigasi & Keterangan \\
\hline 9 & $\begin{array}{l}\text { Adanya perbedaan } \\
\text { interpretasi dokumen kontrak } \\
\text { antara owner } \\
\text { dengan kontraktor }\end{array}$ & 6 & $\begin{array}{l}\text { mengadakan rapat membahas isi } \\
\text { dan ketentuan dalam kontrak dan } \\
\text { jika diperlukan membuat nota } \\
\text { kesepahaman (MoU) untuk } \\
\text { menyamakan intepretasi isi dan } \\
\text { ketentuan kontrak }\end{array}$ & $\begin{array}{l}\text { Untuk } \\
\text { menghindari } \\
\text { addendum }\end{array}$ \\
\hline 10 & $\begin{array}{l}\text { Kontraktor tidak } \\
\text { mengajukan contoh material } \\
\text { untuk disetujui terlebih } \\
\text { dahulu oleh konsultan } \\
\text { pengawas }\end{array}$ & 8 & $\begin{array}{l}\text { konsultan pengawas kepada } \\
\text { kontraktor lewat lisan atau } \\
\text { tertulis tentang kewajiban } \\
\text { kontraktor mengajukan contoh } \\
\text { material untuk disetujui }\end{array}$ & $\begin{array}{l}\text { Untuk } \\
\text { menghindari mutu } \\
\text { tidak sesuai }\end{array}$ \\
\hline 11 & $\begin{array}{l}\text { Pengadaan material yang } \\
\text { tidak sesuai dengan } \\
\text { spesifikasi teknis }\end{array}$ & 12 & $\begin{array}{l}\text { Menginstruksikan dan memberi } \\
\text { teguran kepada kontraktor untuk } \\
\text { mengganti material yang tidak } \\
\text { sesuai dengan yang disyaratkan }\end{array}$ & $\begin{array}{l}\text { Untuk } \\
\text { menghindari mutu } \\
\text { tidak sesuai }\end{array}$ \\
\hline 12 & $\begin{array}{l}\text { Kurangnya kualitas } \\
\text { pekerjaan karena lemahnya } \\
\text { pengawasan lapangan }\end{array}$ & 8 & $\begin{array}{l}\text { Meningkatkan frekuensi } \\
\text { kedatangan konsultan di lapangan } \\
\text { untuk melakukan pengawasan } \\
\text { yang lebih ketat terhadap } \\
\text { pekerjaan kontraktor. }\end{array}$ & $\begin{array}{l}\text { Untuk } \\
\text { menghindari mutu } \\
\text { tidak sesuai }\end{array}$ \\
\hline 13 & $\begin{array}{l}\text { Kurangnya kualitas } \\
\text { pekerjaan karena tidak } \\
\text { mengikuti dan melaksanakan } \\
\text { masukan dan instruksi dari } \\
\text { pengawas Lapangan }\end{array}$ & 8 & $\begin{array}{l}\text { Memberikan instruksi kepada } \\
\text { kontraktor untuk mengikuti } \\
\text { masukan dan selalu } \\
\text { berkoordinasi dengan konsultan } \\
\text { pengawas }\end{array}$ & $\begin{array}{l}\text { Untuk } \\
\text { menghindari mutu } \\
\text { tidak sesuai }\end{array}$ \\
\hline 14 & $\begin{array}{l}\text { Kurangnya kelengkapan } \\
\text { pengamanan proyek yang } \\
\text { dapat menyebabkan } \\
\text { Kecelakaan }\end{array}$ & 6 & $\begin{array}{l}\text { Menambahkan pagar pengaman } \\
\text { dan pertanda (signage) untuk } \\
\text { mencegah kecelakaan, melarang } \\
\text { pihak-pihak yang tidak } \\
\text { berkepentingan memasuki areal } \\
\text { proyek dan menempatkan petugas } \\
\text { keamanan khusus }\end{array}$ & $\begin{array}{l}\text { Untuk } \\
\text { menghindari } \\
\text { Kecelakaan } \\
\text { Kerja }\end{array}$ \\
\hline 15 & $\begin{array}{l}\text { Tenaga kerja yang } \\
\text { diperlukan kurang } \\
\text { mencukupi }\end{array}$ & 8 & $\begin{array}{l}\text { a. Membuat schedule dan metode } \\
\text { kerja (man power) tentang } \\
\text { kebutuhan tenaga kerja sesuai } \\
\text { dengan lingkup dan waktu } \\
\text { pelaksanaan proyek } \\
\text { b. Mengagendakan kerja lembur } \\
\text { untuk antisipasi item-item } \\
\text { pekerjaan yang membutuhkan } \\
\text { banyak tenaga kerja }\end{array}$ & $\begin{array}{l}\text { Untuk } \\
\text { menghindari } \\
\text { addendum }\end{array}$ \\
\hline 16 & $\begin{array}{l}\text { Koordinasi antara } \\
\text { kontraktor, konsultan } \\
\text { perencana, konsultan } \\
\text { pengawas dan owner } \\
\text { kurang berjalan dengan baik }\end{array}$ & 6 & $\begin{array}{l}\text { Meningkatkan koordinasi antara } \\
\text { kontraktor dan konsultan } \\
\text { pengawas juga pihak owner dan } \\
\text { memperketat pengawasan oleh } \\
\text { konsultan pengawas agar } \\
\text { pekerjaan sesuai dengan yang } \\
\text { direncanakan }\end{array}$ & $\begin{array}{l}\text { Untuk } \\
\text { menghindari } \\
\text { addendum }\end{array}$ \\
\hline 17 & $\begin{array}{l}\text { Terjadinya keterlambatan } \\
\text { penyelesaian proyek }\end{array}$ & 9 & $\begin{array}{l}\text { a. Meningkatkan prestasi kerja } \\
\text { misalnya dengan enambah jam }\end{array}$ & $\begin{array}{l}\text { Untuk } \\
\text { menghindari } \\
\text { addendum }\end{array}$ \\
\hline
\end{tabular}




\begin{tabular}{|c|c|c|c|c|}
\hline No & Faktor Risiko & \begin{tabular}{|c|} 
Nilai \\
Risiko \\
\end{tabular} & Tindakan Mitigasi & Keterangan \\
\hline & & & $\begin{array}{l}\text { kerja lembur bagi tenaga kerja } \\
\text { untuk mengejar Keterlambatan } \\
\text { b. Melakukan perbaikan metode } \\
\text { kerja dengan mengutamakan } \\
\text { pekerjaan } \\
\text { c. Mengajukan permohonan } \\
\text { penambahan waktu pelaksanaan } \\
\text { pekerjaan kepada owner untuk } \\
\text { mengejar keterlambatan yang } \\
\text { terjadi }\end{array}$ & \\
\hline 18 & $\begin{array}{l}\text { Adanya perbedaan } \\
\text { Perhitungan volume } \\
\text { pekerjaan yang telah } \\
\text { dikerjakan antara kontraktor } \\
\text { dan konsultan pengawas }\end{array}$ & 6 & $\begin{array}{l}\text { Melakukan perhitungan ulang } \\
\text { bersama-sama di lapangan oleh } \\
\text { konsultan pengawas dan } \\
\text { kontraktor dengan disaksikan } \\
\text { oleh direksi dari pihak owner } \\
\text { untuk mendapatkan kesepakatan } \\
\text { volume di lapangan }\end{array}$ & $\begin{array}{l}\text { Untuk } \\
\text { menghindari } \\
\text { volume yang tidak } \\
\text { sesuai }\end{array}$ \\
\hline \multicolumn{5}{|c|}{ C. Risiko Teknis } \\
\hline 19 & $\begin{array}{l}\text { Perbedaan hasil pengukuran } \\
\text { kualitas dan kuantitas } \\
\text { pekerjaan dengan kondisi } \\
\text { aktual di lapangan } \\
\end{array}$ & 8 & $\begin{array}{l}\text { mengadakan pengukuran ulang } \\
\text { untuk mendapatkan hasil } \\
\text { pengukuran yang disepakati }\end{array}$ & $\begin{array}{l}\text { Untuk } \\
\text { menghindari } \\
\text { addendum }\end{array}$ \\
\hline 20 & $\begin{array}{l}\text { Adanya perubahan disain } \\
\text { akibat penyesuaian dengan } \\
\text { kondisi di Lapangan }\end{array}$ & 9 & $\begin{array}{l}\text { Melakukan koordinasi antara } \\
\text { kontraktor, konsultan pengawas } \\
\text { dan konsultan perencana untuk } \\
\text { kemudian dilakukan perubahan } \\
\text { disain sesuai kondisi di lapangan }\end{array}$ & $\begin{array}{l}\text { Untuk } \\
\text { menghindari } \\
\text { kesalahan } \\
\text { pekerjaan }\end{array}$ \\
\hline 21 & $\begin{array}{l}\text { Peralatan yang digunakan } \\
\text { terutama alat berat dan } \\
\text { kendaraan pengangkut tanah } \\
\text { dan material lain tidak } \\
\text { mencukupi sehingga } \\
\text { menghambat pekerjaan }\end{array}$ & 6 & $\begin{array}{l}\text { a. Membuat schedule dan metode } \\
\text { kerja untuk efektivitas } \\
\text { penggunaan alat } \\
\text { b.Menambah armada dari sub } \\
\text { kontraktor lain untuk } \\
\text { memperlancar pekerjaan }\end{array}$ & $\begin{array}{l}\text { Untuk } \\
\text { menghindari } \\
\text { addendum }\end{array}$ \\
\hline \multicolumn{5}{|c|}{ D. Risiko Lingkungan } \\
\hline 22 & $\begin{array}{l}\text { Sulitnya akses masuk bagi } \\
\text { alat berat yang akan } \\
\text { digunakan } \\
\text { selama pelaksanaan proyek }\end{array}$ & 6 & $\begin{array}{l}\text { Menyiapkan akses alternatif untuk } \\
\text { memasukkan alat berat dan } \\
\text { melakukaan koordinasi dengan } \\
\text { pihak keamanan }\end{array}$ & $\begin{array}{l}\text { Untuk } \\
\text { menghindari } \\
\text { addendum }\end{array}$ \\
\hline \multicolumn{5}{|c|}{ E. Risiko Kesehatan } \\
\hline 23 & $\begin{array}{l}\text { Kurangnya pengamanan di } \\
\text { lokasi proyek }\end{array}$ & 9 & $\begin{array}{l}\text { Menambahkan pagar pengaman } \\
\text { dan pertanda untuk mencegah } \\
\text { kecelakaan, melarang pihak-pihak } \\
\text { lain yang memasuki areal proyek }\end{array}$ & $\begin{array}{l}\text { Untuk } \\
\text { menghindari } \\
\text { addendum }\end{array}$ \\
\hline F. & Risiko Ekonomi & & & \\
\hline 24 & $\begin{array}{l}\text { Terjadinya eskalasi atau } \\
\text { kenaikan harga bahan } \\
\text { bangunan selama } \\
\text { masa pelaksanaan } \\
\text { Konstruksi }\end{array}$ & 12 & $\begin{array}{l}\text { a. Kontraktor melakukan order } \\
\text { atau pemesanan material sejak } \\
\text { untuk mengantisifasi eskalasi } \\
\text { harga } \\
\text { b. Mencari supplier material } \\
\text { alternatif yang menawarkan } \\
\text { harga lebih murah }\end{array}$ & $\begin{array}{l}\text { Untuk } \\
\text { menghindari } \\
\text { addendum }\end{array}$ \\
\hline
\end{tabular}




\begin{tabular}{l|l|c|l|l}
\hline No & \multicolumn{1}{|c}{ Faktor Risiko } & $\begin{array}{l}\text { Nilai } \\
\text { Risiko }\end{array}$ & \multicolumn{1}{c}{ Tindakan Mitigasi } & Keterangan \\
\hline 25 & $\begin{array}{l}\text { Terjadinya kenaikan harga } \\
\text { bahan bakar minyak selama } \\
\text { kmasa pelaksanaan } \\
\text { pekerjaan } \\
\text { yang akan mempengaruhi } \\
\text { kinerja proyek }\end{array}$ & 12 & $\begin{array}{l}\text { Menerapkan strategi penghematan } \\
\text { penggunaan BBM dengan efisiensi } \\
\text { penggunaan alat yang memerlukan } \\
\text { konsumsi BBM tinggi. }\end{array}$ & $\begin{array}{l}\text { Untuk } \\
\text { menghindari } \\
\text { addendum }\end{array}$ \\
\hline G. Risiko Kimiawi & $\begin{array}{l}\text { Hilangnya material dan } \\
\text { peralatan kerja selama } \\
\text { berlangsungnya royek }\end{array}$ & 9 & $\begin{array}{l}\text { Memperketat akses masuk ke } \\
\text { proyek khususnya areal gudang } \\
\text { untuk mengantisipasi pencurian } \\
\text { material maupun alat kerja } \\
\text { mengan menempatkan petugas } \\
\text { keamanan khusus }\end{array}$ & $\begin{array}{l}\text { Untuk } \\
\text { menghindari }\end{array}$ \\
\hline 27 & $\begin{array}{l}\text { Terjadinya perusakan } \\
\text { fasilitas } \\
\text { Proyek }\end{array}$ & 8 & $\begin{array}{l}\text { Mensterilkan lokasi proyek dari } \\
\text { pihak-pihak yang tidak } \\
\text { berkepentingan }\end{array}$ & $\begin{array}{l}\text { Untuk } \\
\text { menghindari } \\
\text { addendum }\end{array}$ \\
\hline I. Risiko Keuangan & $\begin{array}{l}\text { Adanya keterlambatan } \\
\text { pembayaran oleh kontraktor } \\
\text { kepada suplayer bahan/ } \\
\text { material bangunan }\end{array}$ & 9 & $\begin{array}{l}\text { Membuat kontrak kerja yang jelas } \\
\text { agar aturan dalam kontrak } \\
\text { tersebut menjadi acuan hak dan } \\
\text { kewajiban antara kedua belah } \\
\text { pihak }\end{array}$ & $\begin{array}{l}\text { Untuk } \\
\text { menghindari } \\
\text { addendum }\end{array}$ \\
\hline 29 & $\begin{array}{l}\text { Keterlambatan pembayaran } \\
\text { oleh kontraktor utama } \\
\text { kepada pihak sub kontraktor }\end{array}$ & 9 & $\begin{array}{l}\text { Membuat suatu kontrak kerja } \\
\text { yang jelas untuk mencegah } \\
\text { keterlambatan pembayaran }\end{array}$ & $\begin{array}{l}\text { Untuk } \\
\text { menghindari } \\
\text { addendum }\end{array}$ \\
\hline
\end{tabular}

